\title{
„Композитный взрыв” в современном русском газетном дискурсе
}

\section{Введение}

В современном русском газетном дискурсе заметна популярность сложных слов. В настоящее время сложные единицы находятся в центре постоянных исследований, так как статус многих из них является предметом споров. Однако в связи с тем, что в течение последних десятилетий популярность сложения как способа языковой номинации значительно усилилась, появилась потребность изучения этого лингвистического феномена.

Цель настоящей работы - исследовать структурно-морфологический и графический аспекты композитов, провести тематическую классификацию собранных единиц, а также выявить причины популярности сложных слов в современном русском языке. Эмпирическим материалом послужили тексты из российских глянцевых журналов, опубликованных в 2013-2016 годах («Добрые советы», «Домашний Очаг», «Магия и красота», «Между нами женщинами», «Стильные причёски», «Allure», «Cosmopolitan», «Glamour», «Elle»). Выбор источника исследования не случаен. Как подчёркивает Елена Земская, сфера употребления сложных слов ограничена, так как они главным образом встречаются в публицистике и специализированной прессе ${ }^{1}$. Выбранные периодические издания условно определяются «женскими журналами», поэтому тематический круг ограничен целевой аудиторией. Однако, анализируя определённый фрагмент языковой действительности, можно заметить общие тенденции эволюции языка в медиадискурсе.

${ }^{1}$ Е.А. Земская, Словообразование как деятельность, Москва 2005, с. 48. 
Динамика развития словосложения в современном русском языке определятся лингвистами как «композитный взрыв»². Польские и российские учёные замечают активизацию употребления сложений в русском языке. Интересные публикации, посвящённые сложным единицам языка, написаны польским языковедом Михалом Блихарским ${ }^{3}$. Ещё в семидесятых годах $\mathrm{XX}$ века он, анализируя композиты русского и польского языков, отмечал их возрастающую роль в системе дериватологии. Многие российские лингвисты также описывали этот языковой феномен, например, Евгения Василевская, Светлана Гудилова, Татьяна Кочеткова, Леонид Крысин, Елена Кубрякова, Рахим Хашимов ${ }^{4}$. Сложные слова широко представлены в современном русском языке медийного дискурса.

В настоящей статье термин композит (лат. composito - составление, сложение, сочетание) понимается в широком смысле. Именно в таком смысле этот термин используется и во многих научных трудах и словарях лингвистических терминов и употребляется как дублет сложного слова ${ }^{5}$. По мнению Натальи Спицыной, сложения - это слова, в структуре которых выделяются минимум два компонента (основы, слова, также аббревиатуры), связанные общим значением ${ }^{6}$. Важно, что в группу исследуемых сложных слов включены различные двухкомпонентные единицы независимо от способа их образования. Такой подход обусловлено тем, что генеалогия сложных слов, функционирующих в русском языке, неоднородна. Одни композиты образовались путём сложения на русской почве, другие были заимствованы из иностранных языков, в подавляющем большинстве из английского. В русском языке новейшего периода, обусловлен в медийном пространстве, заметна языковая миграция не только отдельных слов, композитных единиц, но также словообразовательных моделей, используемых в процессе деривации неологизмов.

Композитосложение главным образом характерно для образования имён существительных и прилагательных. В собранном материале центральное место занимают существительные, и именно они подвергаются настоящему анализу.

2 Н.А. Николина, Е.А. Фролова, М.М. Литвинова, Словообразование современного русского языка, Москва 2005, с. 129.

${ }^{3}$ M. Blicharski, Złożenia rzeczownikowe współczesnego języka rosyjskiego, Opole 1973; M. Blicharski, Złożenia imienne w języku rosyjskim i polskim: studium konfrontatywne, Warszawa-Wrocław 1977.

${ }^{4}$ Полный список литературы приведённых авторов находится в конце статьи.

5 Энииклопедический словарь-справочник лингвистических терминов и понятий. Русский язык, т. 1, под общей ред. А.Н. Тихонова, Р.И. Хашимова, Москва 2014, с. 529.

${ }^{6}$ Н.П. Спицына, Сложные наименования одежды в английском, немеиком и русском языках, «Вестнік Беларускага дзяржаунага універсітэта» 2002, серыя 4, с. 67. 


\section{Статус сложных слов: проблемы классификации}

Среди анализируемых языковых единиц находятся собственно сложные слова, которые представляют собой традиционную модель композитообразования (вагинопластика, кинозвезда, кредитомания), но самую обширную группу составляют структуры, лингвистический статус которых является предметом постоянных споров.

В современной русистике спорным является вопрос о том, как классифицировать биномины, то есть образования, состоящие из самостоятельных лексических единиц (бигуди-бумеранги, крем-кисть, массажист-эстетист). Они занимают промежуточное место между словами и словосочетаниями ${ }^{7}$ В конце XX века Виталий Костомаров говорил о растущей значимости этих конструкций, даже считал, что «их распространение носит поистине эпидемический характер» ${ }^{8}$.

Кроме того, среди исследователей отсутствует единое мнение относительно статуса так называемых квазикомпозитов (аквааэробика, женофоб, мини-компьютер). Это сложные структуры, которые характеризуются связанностью составных компонентов (радиксоидов и аффиксоидов) и, самое главное, непроизводностью основы ${ }^{9}$, что отличает их от чистых сложений.

Наконец, затруднения возникают также при рассмотрении заимствованных сложных по своей структуре конструкций (боди-арm, веб-сайт, офис-менеджер), которые не являются объектом русского синхронного словообразования, но появились в результате заимствований из других языков.

В лингвистике до сих пор не проведена чёткая граница между сложными и другими структурными единицами. Среди исследователей нет единого мнения по этому вопросу. В настоящей статье все типы номинаций (биномины, квазикомпозиты и заимствованные сложные конструкции) рассматриваются как композиты. Такое решение обусловлено тем, что все исследуемые единицы, помимо существенной разницы и индивидуальных характеристик, обладают сходными чертами, отличающими композиты от словосочетаний или простых слов, т.е. наличием сложной структуры, принадлежностью к конкретной части речи, морфологической и графической цельнооформленностью.

7 См. А.А. Черкасова, О некоторых грамматических признаках билексемы как основной единиць языка, «Вестник Нижегородского университета им. Н.И. Лобачевского» 2010, 3 (1), c. 347.

8 В.Г. Костомаров, Языковой вкус эпохи. Из наблюдений над речевой практикой массмедиа, Москва 1994, с. 160.

9 Е.В. Клобуков, С.В. Гудилова, Языковая специифика непроизводных сложных слов (квазикомпозитов), [в:] Язык, сознание, коммуникация. Сборник статей, вып. 20, отв. ред. В.В. Красных, А.И. Изотов, Москва 2001, с. 13. 


\section{Тематическая классификация сложных слов}

Исследуемые журналы отличаются политематичностью, лексическим разнообразием, но всё же профиль каждого из них ограничивает сферу словарного состава. Периодика, условно называемая «женской», главным образом посвящена моде, здоровью, красоте, развлечениям, музыке, кино. Многие статьи в этих журналах также затрагивают психологические и социальные проблемы. Итак, предлагаемая лексико-семантическая классификация собранного материала имеет условный характер, так как она осуществляется на ограниченном материале. В группе сложных единиц можно выделить наименования предметов, лиц, а также наименования абстрактных фактов действительности из довольно широкого спектра областей:

- Банковское дело (банк-акиептант, банк-дилер, банк-корреспондент, интернет-платёж, кредитомания, sтs-банкинг, PIN-код);

- Бизнес (бизнес-вумен / бизнесвумен, бизнес-ланч, бизнес-леди, кейтеринг-компания, компания-посредник, медиа-бизнес, фокус-группа);

- Быт и социальная жизнь (альфа-самеи, беби-бум, боди-пирсин, вайд-кард, гей-парад, женофоб, прайс-лист, самопрезентация, секс-игрушки, секс-просвещение, секс-шоп, тайм-менеджмент, фейс-контроль, экспресссвидание, outdoor-поведение, outdoor-обучение, outdoor-реклама, outdoorуроки);

- Гостиничное дело (апарт-отель, бунгало-люкс, джуниор-сьют, лобби-бар, отель-курорт, спа-отель);

- Информатика (веб-сайт, веб-страница, интернет-магазин, интернет-шопинг, мини-компьютер, онлайн-игры);

- Киноискусство (кинозвезда, комеди-шоу, лав-стори, муви-стар, роуд-комеди, роуд-муви, треш-классик, фильм-конвейер, хоум-видео, 3D-зал, 3D-кинотеатр);

- Косметология (бальнеотерапия, блефаропластика, боди-арт, вагинопластика, велнес-клуб, воск-спрей, детокс-курс, детокс-питание, детокспрочедура, детокс-терапия, какао-пилинг, карандаш-фломастер, крем-гель, крем-кисть, крем-краска, крем-мыло, крем-суфле, лак-малютка, лимфодренаж, лосьон-спрей, маммопластика, молочко-распьливатель, нейл-дизайн, пенка-шампунь, подводка-фломастер, релакс-зона, релакс-массаж, румяна-щарики, спа-процедура, спа-терапевт, спа-уход, спа-центр, спа-чудеса, спрей-пудра, стоун-терапия, талассотерапия, талассоцентр, флоат-камера, эко-прочедуры, экспресс-макияж, экспресс-средство, nail-профессионал, nail-специалист, nail-тренд, SPA-оазис, SPA-путешествие, wellness-центр);

- Кулинария (пирог-суфле, слоу-фуд / слоуфуд, снек-бар, стейк-хаус, фаст-фуд / фастфуд, ісе-латте);

- Мода (бохо-шик, бьюти-блог, бьюти-блогер, бьюти-кейс, бюти-индустрия, дресс-код, дресскостюм, топ-модель, сапоги-чулки, секс- 
бюстальтер, трусь-стринг, фешен-икона, bеaиtу-мир, саsиаl-одежда, fashion-журнал, fashion-коллекция, party-гардероб);

- Музыка (брейк-бит, грандж-группа, диджей-зона, диско-хаус, джазфанк, микс-трек, прогрессив-рок, рок-бенд, рок-кавер, хард-рок, хит-парад);

- Наименования профессий и должностей (арm-директор, бизнес-тренер, бьюти-эдитор, врач-дермокосметолог, имидж-мейкер / имиджмейкер, контент-редактор, кофе-мейкер, массажист-эстетист, мастер-колорист, офис-менеджер, секс-тренер, спа-эксперт, топ-стилист, трихолог-клиницист, фотодизайнер, хирург-эстетист, эйчар-менеджер, эксперт-нитрициолог, PR-менеджер, IT-сnецииалист, outdoor-эксперт);

- Парикмахерское искусство (бигуди-бумеранги, каре-боб, мастеркласс, поинт-кат, премиум-класс, смарт-стайлер, фен-дифузор, ииньонькрабы, ииньонь-хвостьл, ииньоньл-косыл, иприц-дозатор, ичипцьь-гофре, щуетка-антистатик);

- Развлечения (стрит-парк, шоу-бизнес, home-party, speed-dating);

- Спорт (аквааэробика, банджи-джампинг, вибротренажер, допингконтроль, допинг-проба, допинг-центр, йога-клуб, йога-студия, квотер-пайп, спаринг-партнер, степ-платформа, топ-атлета, трофи-лига, сноубордпарк, фитнес-нагрузка, фитнес-питание, хаф-пайп, outdoor-активность);

- Технологии (лазер-диск, микрофон-удочка, спам-рассылка, флешкарта, LED-фары, sms-переписка).

В группе исследуемых единиц находятся композиты, позиция которых стабилизирована многолетним функционированием в языке, а также «свежие» неологизмы, которые бывают непонятны многим носителям языка. Речь идёт о композитных номинациях, называющих новые явления в русской социально-культурной жизни, которые перенимаются от других народов, например, outdoor-aктивность, speed-dating. Их лексическое значение трудно понять людям, не знающим английского языка и западной культуры.

\section{Анализ композитов: структурно-морфологический и графический аспекты}

Собранные сложные единицы представляют собой разнообразную по происхождению основ группу единиц, среди которой можно выделить:

- полные чистые заимствования (бокс-офис, бьюти-кейс, вайлд-кард, лав-стори, мастер-класс, рок-кавер, роуд-комеди, роуд-муви, снек-бар, смарт-стайлер, стейк-хаус),

- кальки или полукальки (кинозвезда, фешин-безумие, спаринг-партнёр, человек-паук),

- дериваты, образованные от исконно русских основ или комбинации разных по происхождению основ (бигуди-бумеранги, крем-краска, подводка-фломастер, ииньонь-косы, ииньонь-хвость, иприц-дозатор). 
Учитывая аспект морфологической автономности основ, надо также подчеркнуть, что в структуре композитов выделяются как связанные, так и свободные компоненты. С формальной точки зрения это означает, что сложные слова состоят из полнозначных основ, которые могут употребляться самостоятельно (крем-кисть, интернет-иопинг, румяна-иарики), а в их структуре выступают аффиксоиды и радиксоиды, занимающие промежуточное место между аффиксом и корнем (арт-, бъюти-, -мейкер, мини-, пресс-, таласco-, mon-, -фоб). Эти последние отличаются семантической зависимостью от других компонентов сложений, т.е. не употребляются обычно как автономные слова, только как связанный компонент.

Роль радиксоидов в словообразовании неологизмов заметно усиливается. Одним из активных процессов в русском языке новейшего периода, наблюдаемым в средствах массовой информации, является бурное образование новых словообразовательных гнёзд с формантами аффиксоидного и радиксоидного типа. Так, например, в последнее время в русском языке появилась многочисленная группа слов с элементом mon в значении вершина. Это единицы заимствованы главным образом из английского языка. Они стали прототипом образца, по которому происходят словообразовательные процессы на русской почве. Такие словосложения, как mon-лист, топ-модель / топ-манекенщчица, топ-менеджер, топ-десятка, топ-бизнес, появились в результате «импорта» англоязычных составных наименований, но они быстро адаптировались в новой системе русского языка, образуя группу производных композитов (топ-работники, топ-женщины ).

Интересными единицами являются конструкции с радиксоидом бьюmu / бюти / beauty. Они образуют открытый ряд неологизмов, функционирующих прежде всего в женских журналах, посвящённых моде, красоте и здоровью. Группа данных сложений довольно обширна, например: бьюти-аддикиия, bеaиtу-азбука, бьюти-блог, бьюти-блогер, beauty-выбор, бьюти-гаджет, бьюти-гид, бьюти-график, бьюти-зависимость, бьютизависимылй, бьюти-икона, бюти-индустрия, бьюти-карта, бьюти-кейс, bеаиту-колейдоскоп, бьюти-легенда, бьюти-намерение, bеaиtу-новости, бьюти-маньяк, ьеаиту-мир, ьеаиту-образы, бьюти-правила, бьюти-привычки, бьюти-программа, бьюти-прочедура, бьюти-редактор, бьюти-роды, бьюти-секрет, бьюти-сенсация, бьюти-средство, бьюти-тенденция, бьюти-тренд, бьюти-уход, бьюти-шопинг, bеaиtу-эксперт, бюти-экстаз. Хотелось бы обратить внимание на то, что композитные номинации с элементом бьюти / бюти / beauty стали не только употреблятся в выше указанных рубриках журнала, но они перешли в сферу узуса и обиходного общения. Иногда даже создаётся впечатление, что авторы текстов злоупотребляют такими словообразованиями, тем более что в русском языке существуют лексические эквиваленты многих исследуемых терминов, которые, кажется, в газетном дискурсе становятся периферией. Так слово косметика заменяется выражением бьюти-средство, а секреты красоты называются теперь 
бьюти-секретами. Но некоторые композиты данной группы являются номинациями новых социальных явлений. Например, бьюти-зависимость / бьюти-аддикиия - это болезненное стремление добиться идеальной внешности, называемое также косметическим рабством. Интригующе звучащий неологизм бьюти-роды называет новый тренд в области пластической хирургии, а точнее, вид операции, суть которой заключается в удалении жира и лишней кожи непосредственно после кесарева сечения.

Следующую группу сложных слов образуют конструкции, в структуре которых выделяем аббревиатуры. Такой тип сложений в новейший период отмечается высокой степенью продуктивности. В большинстве исследуемых единиц сокращения находятся в препозиции по отношению ко второму компоненту сложения (BB-крем, VIP-зал, sms-банкинг, sms-конкурс, $P R$-менеджер, IT-специалист, $S O S$-средства), в редких случаях они могут находиться в постпозиции (бар-VIP).

Особого внимания заслуживает орфографический аспект сложных слов. Оказывается, что композиты русского языка новейшего периода отличаются вариативностью их написания. Встречаются разные графические формы одного и того же слова и они существуют в письменных текстах параллельно. Этот факт замечают лексикографы, которые в своих словарях дают всевозможные варианты написания лексем. Надо также подчеркнуть, что такой либеральный подход приводит к нарушению орфографического нормативизма. Слитное написание характерно прежде всего для связанных элементов, которые отличаются низкой степенью семантической автономности. Дефисное написание встречается главным образом в композитах, в составе которых выделяются свободные корни, сохраняющие семантическую независимость. Но в собранном материале заметны многие отклонения от этих правил. Можно даже констатировать, что из-за этого орфографического «беспорядка» появляются иногда сомнения, касающиеся правильной классификации композитов. Проблемы возникают, прежде всего, в случае заимствований, графическая адаптация которых неоднородна. Одни сложные слова пишутся через дефис, другие - слитно, хотя нет между ними резких морфологических границ. Орфографические колебания, возникшие в результате отсутствия строгих норм и правил освоения такого типа иноязычий в русском языке, приводят ко множеству интерпретаций в определении конкретного статуса некоторых слов.

Ещё одно важное замечание. Некоторые заимствованные сложные слова вкрапливаются в русский текст полностью в латинской графике, например: home-party, speed-dating, wish-list. Но многие композиты имеют гибридный характер, т.е. представляют собой структурную комбинацию двух алфавитов (casual-одежда, fashion-журнал, outdoor-активность, wellness-центр). Леонид Крысин говорит о них так: «Кентаврами я называю сложные слова, первая часть которых - иноязычная и пишется при этом латиницей, а вторая русская или также иноязычная, но пишущаяся кириллическим 
шрифтом» ${ }^{10}$. Крысин далее замечает, что такого типа сложения появились в результате влияния английской словообразовательной системы и поэтому ощущаем их «словами-чужаками», которые ограничены сферой употребления и коммуникативными ситуациями. Это не позволяет, по его мнению, считать их полноценными единицами русского языка ${ }^{11}$. Естественно «композиты-кентавры» не соответствуют русской графической норме, но их количество в текстах периодических изданий постоянно растёт ${ }^{12}$, а наиболее употребительные единицы приобретают статус обычных сложных слов. Они становятся прототипом для деривации неологизмов на русской почве. Этот языковой факт показывает, что русский язык не консервативен, а изменяется под влиянием реальности. Данные изменения наступают не только в сфере лексики, но также в словообразовании.

\section{Причины популярности сложных слов}

Причины «композитного взрыва» в медийном пространстве разнообразны. Во-первых, появление сложных слов в лексиконе русского языка обусловлено потребностями наименования новых реалий окружающей действительности. Несомненно, сложные единицы отличаются, с одной стороны, формальной краткостью, а с другой, семантической ёмкостью. Эта существенная черта композитов обеспечивает языковую экономию, тем самым облегчает процесс коммуникации. Тенденция к языковой экономии, по мнению многих лингвистов, является одной из основных черт развития современного русского языка ${ }^{13}$. Композиты особенно интенсивно употребляются в образовании терминов, в номинации новых предметов и фактов действительности, потому что они способны называть сложные в семантическом смысле десигнаты и детализовать их, т.е. они служат средством дифференциации понятий.

Кроме того, важной причиной популярности сложных слов в исследуемых периодических изданиях являются языковые контакты, приводящие к трансферу из иноязычных систем и самой лексики, и словообразовательных моделей. На основании вышепроведённого анализа можно констатировать, что главным донором всякого рода заимствований является

10 Л.П. Крысин, О некоторых новых типах слов в русском языке: слова-«кентавры», «Вестник Нижегородского университета им. Н. И. Лобачевского. Лингвистика» 2010, № 4 (2), c. 575, http://www.unn.ru/pages/issues/vestnik/99999999_West_2010_4(2)/45.pdf [доступ: 26.04.2016].

11 Ibidem, c. 577.

12 A. Romanik, Wjęzykowej komitywie. O angielskich wtrętach językowych w rosyjskich czasopismach specjalistycznych, [w:] W poszukiwaniu tożsamości językowej, t. 1, ред. Ż. Sładkiewicz, K. Wądołowska-Lesner, Gdańsk 2016, c. 174.

${ }^{13}$ A. Pstyga, Nowe slownictwo rosyjskie. Struktura formalna i semantyczna rzeczownika, Gdańsk 1994, c. 8. 
английский язык, который характеризуется высокой степенью аналитизма. Надо заметить, что многие исследуемые журналы издаются на иностранных лицензиях, что в относительно большой степени влияет на содержание текстов, которые пестрят различной информацией из жизни «Запада», описываемой языком с огромным количеством варваризмов. Использование их в письменной речи приводит к популяризации.

Интенсификация употребления композитов в русском языке прессы обусловлена также стилеобразующей функцией. Журналисты заботятся о том, чтобы их тексты привлекали внимание читателей, и поэтому используют разные средства языковой выразительности. Хорошим способом индивидуализации текста являются композиты окказионального характера. Некоторые журналисты изобрели композиты, которые употребляются только в языке их конкретного издания и функционируют эти формы только в пределах одного журнала. Например, в российском издании журнала «Cosmopolitan» встречаются сложения типа Cosmo-девушка (параллельно используется девушка Cosmo), Cosmo-карта, Cosmo-coветь, Cosmo-форум и т.д. Приведённые примеры композитов образуют открытый ряд неологизмов, которые, несомненно, выполняют не только стилеобразующую, но в какой-то степени и манипулятивную функцию. Ведь использование их в языке данного журнала идентифицирует читателя с конкретной сферой престижного мира. Быть Cosmo-девушкой это значит больше, чем быть просто анонимной читательницей данного журнала, это значит принадлежать к избранной среде современных предприимчивых женщин, заботящихся о своём здоровье, красоте и работе, которые согласно космополитической доктрине Сократа и Диогена, хотят быть частью мирового гражданства.

\section{Итоги}

Резюмируя, можно констатировать, что композиты, извлечённые из русскоязычных женских журналов, образуют интересную многочисленную группу номинаций. Они представляют собой бинарные структуры, которые отличаются графическим оформлением, степенью спаянности компонентов, а также этимологическим разнообразием основ. Значительное место занимают единицы, заимствованные из других языков, главным образом - из английского. Следует подчеркнуть, что не только импортируются конкретные слова, но также заметны в русской дериватологии иносистемные модели словосложения, которые становятся продуктивными схемами композитообразования на исконной почве. Исследуемые сложные слова новейшего периода являются очевидным доказательством космополитичности россиян, отражающейся в процессах глобализации и растущей демократизации современного русского языка в медиа-пространстве. Стоит также отметить, что с прагматической точки зрения композиты, будучи экономическим средством деривационной системы, служат прежде всего 
для наименования новых явлений действительности. Многие сложные слова появляются в русском языке в результате вторичной номинации, вступая в ряд синонимических дублетов. Употребление композитов в языке современных журналов обусловлено не только чисто лингвистическими причинами, но разными субъективными потребностями авторов текстов, которые используют их персуазивный потенциал.

\section{Библиография}

Бек У., Космополитическое мировоззрение, Москва 2008.

Василевская Е.А., Словосложение в русском языке (очерки и наблюдения), Москва 1962.

Гудилова С.В., Продуктивные типь образования сложных слов в современном русском языке: на материале неологизмов второй половины ХХ века, Автореферат диссертации на соискание ученой степени кандидата филологических наук, Москва 2005.

Земская Е.А., Словообразование как деятельность, Москва 2005.

Земская Е.А., Современный русский язык. Словообразование, Москва 2005.

Клобуков Е.В., Гудилова С.В., Языковая специфика непроизводных сложных слов (квазикомпозитов), [в:] Язык, сознание, коммуникация. Сборник статей, вып. 20, отв. ред. В.В. Красных, А.И. Изотов, Москва 2001.

Костомаров В.Г., Языковой вкус эпохи. Из наблюдений над речевой практикой масс-медиа, Москва 1994.

Кочеткова Т.И., Словосложение как средство номиначии и предикации в современном русском языке, Оренбург 2004.

Кочеткова Т.И., Карельская Е.Н., Некоторые продуктивные типы словообразовательных моделей сложных существительных в современном русском языке, «Мир науки, культуры, образования» 2011, № 4 (29).

Крысин Л.Н., О некоторых новых типах слов в русском языке: слова-«кентаврыл, «Вестник Нижегородского университета им. Н. И. Лобачевского. Лингвистика» 2010, № 4 (2), с. 575-579, http://www.unn.ru/pages/issues/vestnik/99999999_West_2010_4(2)/45.pdf [доступ: 26.04.2016].

Кубрякова Е.С., Теория номинации и словообразование, Москва 2012.

Кубрякова Е.С., Словосложение как прочесс номинации и его отличительные формальные и содержательные характеристики, [в:] Теоретические основы словосложения и вопросы создания сложных лексических единии. Сборник статей, Пятигорск 1988.

Михайлова И.Д., Радиксоид как вершина словообразовательного гнезда, «Вестник МГПУ. Серия: Филологическое образование» № 1 (12), 2014.

Николина Н.А., Фролова Е.А., Литвинова М.М., Словообразование современного русского языка, Москва 2005.

Спицына Н.П., Сложные наименования одежды в английском, немецком и русском языках, «Вестнік Беларускага дзяржаунага універсітэта» 2002, серыя 4.

Петрухина Е.В., Новые явления в русском словообразовании, http://www.km.ru/referats/333234novye-yavleniya-v-russkom-slovoobrazovanii [доступ: 14.03.2016].

Хашимов Р.И., Билексема как особая единица языка, «Вопросы филологии» 2008, № 4.

Черкасова А.А., О некоторых грамматических признаках билексемы как основной единицы языка, «Вестник Нижегородского университета им. Н.И. Лобачевского» 2010, 3 (1).

Blicharski M., Złożenia imienne w języku rosyjskim i polskim: studium konfrontatywne, Warszawa-Wrocław 1977.

Blicharski M., Złożenia rzeczownikowe wspótczesnego języka rosyjskiego, Opole 1973.

Slavica Wratislaviensia 166, 2018

(C) for this edition by CNS 
Pstyga A., Nowe słownictwo rosyjskie. Struktura formalna i semantyczna rzeczownika, Gdańsk 1994.

Romanik A., Sposoby nominacji odzieży we współczesnym języku rosyjskim, Białystok 2012.

Romanik A., $W$ językowej komitywie. $O$ angielskich wtrętach językowych $w$ rosyjskich czasopismach specjalistycznych, [w:] W poszukiwaniu tożsamości językowej, t. 1, ред. Ż. Sładkiewicz, K. Wądołowska-Lesner, Gdańsk 2016.

\section{"Compounding explosion" in modern Russian journalese discourse}

\section{Summary}

The author of the paper deals with compound words, which are one of active developing phenomena in the journalese texts. Researched material was excerpted from Russian specialized magazines published in 2010-2016. The number of compounds constantly increases. Most of them are borrowed from English or derived from foreign word-formation models. Neologisms, which contain minimum two components in their structure, are productive in journal discourse because of few reasons. First of all, they are used to name new designate as economic way of nomination. Second of all, compound words play manipulative and styling role in written texts. The main aim of the analysis was to research the structure of compound words, to present lexical classification and to point out the reasons of popularity of compound words.

Keywords: Anglicism, composition, compound words, media discourse, Russian language.

\section{„Eksplozja kompozytów” we współczesnym rosyjskim dyskursie medialnym}

\section{Streszczenie}

Przedmiotem zainteresowania niniejszych rozważań są złożenia, których wysoka frekwencja jest szczególnie zauważalna we współczesnym dyskursie prasowym. Materiał egzemplifikacyjny został wyekscerpowany z rosyjskich czasopism, umownie określanych jako „czasopisma kobiece” (2013-2016). Głównym celem podjęcia tego tematu badawczego jest klasyfikacja leksykalnosemantyczna zgromadzonych jednostek złożonych, analiza strukturalna oraz ustalenie przyczyn ich rosnącej popularności. Istotą badania jest również zwrócenie uwagi na problem niestabilności ortograficznej i graficznej kompozytów zapożyczonych z innych systemów językowych, a także zaakcentowanie braku jednolitej bazy teoretycznej przy klasyfikacji statusu słów złożonych.

Słowa kluczowe: anglicyzm, dyskurs prasowy, język rosyjski, kompozyt, złożenie. 